\title{
RISK FACTORS FOR EARLY POSTOPERATIVE ARRHYTHMIAS IN GENERAL SURGERY PATIENTS AFTER GENERAL ANESTESIA
}

Milivoje Dostic ${ }^{1}$, Vesna Putic ${ }^{1}$, Slobodan Novokmet ${ }^{1}$ and Slobodan M. Jankovic

${ }^{1}$ Medical Faculty, University of Kragujevac, Kragujevac, Serbia

\section{FAKTORI RIZIKA ZA NASTANAK POSTOPERATIVNE ARITMIJE KOD PACIJENATA OPERISANIH U OPŠTOJ ANESTEZIJI}

\author{
Milivoje Dostić ${ }^{1}$, Vesna Putić ${ }^{1}$, Slobodan Novokmet ${ }^{1}$ i Slobodan M. Janković \\ Univerzitet u Kragujevcu, Medicinski fakultet, Kragujevac, Srbija
}

\section{ABSTRACT}

Introduction. Early post-operative arrhythmias after general anaesthesia are serious clinical problems for a significant portion of surgical patients. The aim of our study was to investigate the risk factors for the onset of post-operative arrhythmias in general surgery patients undergoing general anaesthesia.

Methods. In this case-control study, the cases were patients with at least one episode of arrhythmias in the first 24 hours after general anaesthesia $(n=56)$, and the controls were sex and age matched surgical patients $(n=91)$ without post-operative arrhythmias.

\section{INTRODUCTION}

In the immediate postoperative period (the first 24 hours after surgery), arrhythmias requiring the administration of antiarrhythmic therapy occur in 6 to $30 \%$ of patients. The majority of these arrhythmias are of supraventricular origins $[1,2]$. Early postoperative supraventricular arrhythmias are especially frequent and could have profound adverse effects on a patient's outcome $[1,2]$.

Previously, numerous potential risk factors for early post-operative arrhythmias were evaluated, and some of the risk factors were significant. The important risk factors identified include smoking, increased age, atrial enlargement, reduced left ventricular function (especially if ejection fraction is less than $40 \%$ ), preoperative arrhythmias and angina pectoris $[3,4,5,6,7]$. There are also other factors that could influence the frequency of early post-operative arrhythmias, such as previous medications, concomitant medications during general anaesthesia, previous diseases, etc. The aim of our study was to analyse new potential risk factors associated with early post-operative arrhythmias in general surgery patients undergoing general anaesthesia.
Results. A history of cardiac arrhythmias in the last 5 years was a significant risk factor for early post-operative arrhythmias (OR ${ }_{\text {adiusted }}$ 8.43; CI 2.67, 27.13; p = 0.000). Early post-operative arrhythmias occurred more frequently if the patient had a history of cardiac arrhythmias and intra-operative arrhythmias occurred. A history of cardiac arrhythmias and the use of propofol for the induction of anaesthesia were also significant.

Conclusions. In patients with a history of arrhythmias in the last 5 years, general anaesthesia should not be induced by propofol.

Key Words. Post-operative arrhythmias, risk factors, general anaesthesia, propofol.

\section{MATERIALS AND METHODS}

\section{Setting}

Our study was conducted as part of a wider investigation in early postoperative arrhythmias in a secondary general hospital in Foča, Republic of Srpska, Bosnia and Herzegovina. The inclusion criteria for participants wasere elective non-cardiovascular or non-thoracic surgeries, under general inhalation anaesthesia in the Foča hospital. Patients over the 12 year period had to be an American Society of Anaesthesiologists (ASA) class I or II $(\mathrm{n}=520)$. The data were obtained retrospectively from medical records and patient questionnaires. There was ECG-monitoring during anaesthesia and for two days after recovery using a Lifescope 8 Nihon-Kodhen, Datae Ohmeda monitor. All patients supplied written consent, and the Ethics Committee of the Foča hospital approved the study protocol.

The same type of general anaesthesia was used in all study patients. The anaesthetic protocol included balanced general inhalation anaesthesia with a nitrous oxide/oxygen mixture $(3.61: 11)$ and sevoflurane. Controlled mechani- 
cal ventilation was initiated after endotracheal intubation (Sulla 808 V, Fabius Tiro Drager, Datex Ohmeda and Safer 100 AKA). Anaesthesia was induced with either sodium thiopental (3 mg/kg) or propofol ( $2 \mathrm{mg} / \mathrm{kg})$. Muscle relaxation was achieved with succinylcholine $(1-1.5 \mathrm{mg} / \mathrm{kg})$ and maintained with pancuronium bromide $(0.05 \mathrm{mg} / \mathrm{kg})$. For intra-operative analgesia, intravenous fentanyl $(0.005 \mathrm{mg} /$ $\mathrm{kg}$ ) was used. The neuro-muscular blockade was reversed by intravenous neostigmine $(2.5 \mathrm{mg})$ after the operation was completed.

\section{Study design: cases and controls}

This was a case-control study. Both cases and controls were selected from the list of adult patients (ASA class I and II) operated on using general anaesthesia during the study period at Foča hospital. The patients with ECG records of early post-operative arrhythmias (supraventricular extrasystoles, supraventricular tachycardia, supraventricular flutter or fibrillation, sinus tachycardia (frequency > 110/min), sinus bradycardia (frequency < 50), ventricular extrasystoles, ventricular tachycardia, or all types of heart block) in the first 24 hours after surgery, were considered to be our cases. For each case, at least one sex and age-matched control, without any early postoperative arrhythmias, was randomly selected from the study population.

\section{Potential risk factors}

In order to identify potential risk factors, the following data on habits, previous medical history, (co)medications and (co)morbidities were collected from each patient: age, sex, body mass index, profession, type of work (sedentary or active), amount of physical activity, type of surgery, name of surgeon, invasiveness of the surgical technique (as estimated by an anaesthesiologist), duration of general anaesthesia, duration of surgery, type of intravenous anaesthetic, total dose of pancuronium, total dose of fentanyl, intravenous administration of Ringer's solution or hydroxyethyl starch solution during anaesthesia, total volume of each solution given, concomitant diseases like heart failure or arterial hypertension (> 160/95 $\mathrm{mmHg}$ for more than 3 months prior to hospitalisation), diabetes mellitus type 1 or 2 , or chronic obstructive pulmonary disease (COPD), a history of cardiac arrhythmias in the last 5 years and the type of the arrhythmia, and hypertrophy of the left ventricle. The use of the following drugs, for at least 3 months prior to hospitalizsation, were recorded: beta blockers, angiotensin-converting enzyme inhibitors (ACE inhibitors), diuretics, aminophylline, digoxin, antiaggregatory agents, organic nitrates, oral antidiabetics, antipsychotic or antidepressant, antiarrhythmics, pre-operative antibiotic prophylaxis, and pre-operative thromboprophylaxis. The following habits and diagnostic test results were also recorded: smoking (more than 10 cigarettes per day, for at least the previous 2 years), average number of cigarettes per day, alcohol consumption (more than the equivalent of $25 \mathrm{ml}$ of absolute alcohol daily, for the past 3 years), average consumption of alcohol daily, coffee intake (more than 3 cups everyday for the last 2 years), average number of coffee cups per day, hypoxia $\left(\mathrm{SpO}_{2}<96 \%\right)$, hypothermia (core body temperature below $35^{\circ} \mathrm{C}$ ), abnormal levels of serum sodium, potassium, chloride, calcium and magnesium (according to normal reference values for the local biochemical laboratory in Foča hospital), acidosis $(\mathrm{pH}<7.4)$, hypercarbia $\left(\mathrm{pCO}_{2}>45 \mathrm{mmHg}\right.$ ), anaemia (haemoglobin level below $10 \mathrm{~g} / \mathrm{l})$, hyperglycaemia ( $>6.5 \mathrm{mM} / \mathrm{l})$, hypoglycaemia $(<3.5 \mathrm{mM} / \mathrm{l})$, a history of myocardial infarction during the last 5 years, time elapsed from the myocardial infarction, abnormal ECG anytime in the last 5 years and the type of ECG finding, a history of valvular disease and its type, chronic cough (more than 3 months per year for the last 2 years), bronchial asthma, pneumonia, abnormal pulmonary ventilation tests prior to hospitalisation, a history of cerebro-vascular accident, uncontrolled postoperative pain, anti-arrhythmic therapy administered during the surgery, levels of standard biochemical blood tests (cholesterol, glucose, bilirubin, amino-transferases, creatinine, urea, total protein level, albumin level), levels of standard haematology tests (erythrocyte count, leukocyte count, platelet count, haemoglobin level), blood level of C-reactive protein and blood transfusion. The values of laboratory tests refer to the blood samples taken 12 hours prior to surgery.

\section{Data analysis}

The frequency of each risk factor was determined for both cases and controls. The differences between cases and controls, according to observed characteristics, were assessed by Student's T-test for continuous variables and the Chi-squared test or Fisher's test for frequencies. The differences were considered significant if the probability of the null hypothesis was less than 0.05 . In order to estimate the association between potential risk factors and post-operative arrhythmias, crude and adjusted odds ratios (OR), with a $95 \%$ confidence interval $(95 \% \mathrm{CI})$, were calculated using a logistic regression [8.9].

\section{RESULTS}

Among 147 study patients, fifty-six patients (38\%) had at least one episode of an early post-operative arrhythmia. The following types of post-operative arrhythmias were recorded: sinus tachycardia (21 cases, 38\%), supraventricular extrasystole (25 cases, 45\%), paroxysmal supraventricular tachycardia (4 cases, 7\%) and ventricular extrasystole (14 cases, 25\%). Eight patients (15\%) had more than one type of post-operative arrhythmia. There were 91 sex and agematched control patients.

Baseline characteristics of cases and controls, and differences between them, are shown in Table 1. Significant differences between cases and controls were only found only in the following variables: type of intravenous anaes- 
Table 1. Baseline characteristics of cases and controls*.

\begin{tabular}{|c|c|c|c|c|}
\hline Variable & Cases $(n=56)$ & Controls $(n=91)$ & $\begin{array}{l}\text { Test value and significance } \\
\text { of null hypothesis }\end{array}$ & $\begin{array}{l}\text { Crude odds ratios } \\
\text { with confidence } \\
\text { intervals }(1.96 * \mathrm{SE})\end{array}$ \\
\hline $\operatorname{Sex}(M / F)$ & $19 / 37(34 \% / 66 \%)$ & $36 / 55(40 \% / 60 \%)$ & $\chi^{2}=0.470, p=0.493$ & $0.78(0.41,1.51)$ \\
\hline Age (years, mean \pm SD) & $71.1 \pm 10.8$ & $67.8 \pm 10.7$ & $\mathrm{~T}=-1.824, \mathrm{p}=0.071$ & $1.03(0.99,1.06)$ \\
\hline BMI $($ mean \pm SD) & $26.1 \pm 3.8$ & $26.2 \pm 4.2$ & $\mathrm{~T}=0213, \mathrm{p}=0.832$ & $0.99(0.91,1.08)$ \\
\hline Level of education & $\begin{array}{l}\text { High } 1(2 \%) \\
\text { Middle } 5(9 \%) \\
\text { Low } 50(89 \%)\end{array}$ & $\begin{array}{l}\text { High } 4(5 \%) \\
\text { Middle } 23(25 \%) \\
\text { Low } 64(70 \%)\end{array}$ & $\chi^{2}=7.293, p=0.065$ & $0.63(0.42,0.95)$ \\
\hline Name of the surgeon & $\begin{array}{l}\text { Not shown due } \\
\text { to limited space } \\
\text { (16 surgeons) }\end{array}$ & $\begin{array}{l}\text { Not shown due } \\
\text { to limited space } \\
\text { (15 surgeons) }\end{array}$ & $\chi^{2}=12.354, p=0.578$ & $0.98(0.92,1.04)$ \\
\hline Rough surgical technique & $18(32 \%)$ & $25(27 \%)$ & $\chi^{2}=0.465, p=0.793$ & $1.25(0.62,2.52)$ \\
\hline $\begin{array}{l}\text { Type of intravenous anaesthetic } \\
\text { (propofol vs. thiopental) }\end{array}$ & $27 / 29(48 \% / 52 \%)$ & $22 / 69(24 \% / 76 \%)$ & $\chi^{2}=9.014, p=0.003^{*}$ & $2.92(1.47,5.79)$ \\
\hline Ringer's solution administered & $22(39 \%)$ & $31(34 \%)$ & $\chi^{2}=0.410, p=0.522$ & $1.25(0.65,2.42)$ \\
\hline Hydroxyethyl starch solution administered & $13(23 \%)$ & $8(9 \%)$ & $\chi^{2}=5.889, p=0.015^{* *}$ & $3.14(1.22,8.04)$ \\
\hline Smoker & $34(61 \%)$ & $59(65 \%)$ & $\chi^{2}=0.253, p=0.615$ & $0.84(0.46,1.54)$ \\
\hline Alcohol intake & $13(23 \%)$ & $25(28 \%)$ & $\chi^{2}=0.328, p=0.567$ & $0.80(0.38,1.69)$ \\
\hline Coffee intake & $52(93 \%)$ & $85(93 \%)$ & $\chi^{2}=0.017, \mathrm{p}=0.898$ & $0.92(0.32,2.62)$ \\
\hline Sedentary job & $5(9 \%)$ & $10(11 \%)$ & $\chi^{2}=0.161, p=0.689$ & $0.79(0.26,2.42)$ \\
\hline Prior myocardial infarction & $3(5 \%)$ & $8(9 \%)$ & $\chi^{2}=0.591, p=0.442$ & $0.59(0.15,2.29)$ \\
\hline Stable angina pectoris & $7(13 \%)$ & $11(12 \%)$ & $\chi^{2}=0.005, p=0.941$ & $1.04(0.38,2.82)$ \\
\hline History of cardiac arrhythmias & $37(66 \%)$ & $10(11 \%)$ & $\chi^{2}=48.359, \mathrm{p}=0.000^{* * *}$ & $15.77(6.79,36.64)$ \\
\hline History of ECG abnormalities & $43(77 \%)$ & $28(31 \%)$ & $\chi^{2}=29.397, \mathrm{p}=0.000^{* * *}$ & $7.44(3.56,15.54)$ \\
\hline Hypertrophy of the left ventricle & $10(18 \%)$ & $12(13 \%)$ & $\chi^{2}=0.594, p=0.441$ & $1.43(0.58,3.53)$ \\
\hline Hypertension & $43(77 \%)$ & $61(67 \%)$ & $\chi^{2}=1.593, p=0.207$ & $1.92(0.93,3.96)$ \\
\hline Concomitant COPD & $20(36 \%)$ & $26(29 \%)$ & $\chi^{2}=0.823, p=0.364$ & $1.39(0.70,2.75)$ \\
\hline History of cerebro-vascular accident & $9(16 \%)$ & $7(8 \%)$ & $\chi^{2}=2.509, p=0.113$ & $2.29(0.81,6.49)$ \\
\hline Concomitant diabetes & $12(21 \%)$ & $17(19 \%)$ & $\chi^{2}=0.165, p=0.684$ & $1.19(0.53,2.66)$ \\
\hline Hyperglycaemia & $17(30 \%)$ & $27(30 \%)$ & $\chi^{2}=0.008, p=0.930$ & $1.03(0.51,2.08)$ \\
\hline Hypocalcaemia & $31(55 \%)$ & $46(51 \%)$ & $\chi^{2}=0.321, p=0.571$ & $1.21(0.65,2.25)$ \\
\hline Chronic use of beta blockers & $16(29 \%)$ & $19(21 \%)$ & $\chi^{2}=1.131, p=0.288$ & $1.52(0.72,3.20)$ \\
\hline Chronic use of loop diuretics & $15(28 \%)$ & $6(7 \%)$ & $\chi^{2}=11.543, \mathrm{p}=0.001^{* * *}$ & $5.18(1.90,14.16)$ \\
\hline Chronic use of digoxin & $13(23 \%)$ & $3(3 \%)$ & $\chi^{2}=14.178, p=0.000^{* * *}$ & $4.06(1.33,12.41)$ \\
\hline Chronic use of aminophylline & $6(11 \%)$ & $0(0 \%)$ & Fisher's exact test, $\mathrm{p}=0.033^{* * *}$ & $109.20(0.20,56670.27)$ \\
\hline Chronic use of antiaggregatory agents & $14(25 \%)$ & $17(17 \%)$ & $\chi^{2}=0.382, p=0.362$ & $1.45(0.66,3.17)$ \\
\hline Chronic use of organic nitrates & $14(25 \%)$ & $14(15 \%)$ & $\chi^{2}=2.079, p=0.149$ & $1.83(0.81,4.13)$ \\
\hline Total dose of fentanyl (mg/kg) & $0.0086 \pm 0.034$ & $0.0094 \pm 0.027$ & $\mathrm{~T}=1.621, \mathrm{p}=0.107$ & $0.00(0.00,8.22)$ \\
\hline Duration of surgery (minutes) & $95.4 \pm 36.7$ & $91.7 \pm 38.9$ & $\mathrm{~T}=-0.558, \mathrm{p}=0.578$ & $1.00(0.99,1.01)$ \\
\hline Total dose of hydroxyethyl starch solution (ml/kg) & $1.62 \pm 3.16$ & $0.68 \pm 2.27$ & $\mathrm{~T}=-2.093, \mathrm{p}=0.038^{* * *}$ & $1.14(1.00,1.29)$ \\
\hline Serum level of total cholesterol $(\mathrm{mM} / \mathrm{l})$ & $5.10 \pm 1.22$ & $5.60 \pm 1.20$ & $\mathrm{~T}=2.363, \mathrm{p}=0.019^{* *}$ & $0.72(0.54,0.95)$ \\
\hline Intra-operative arrhythmia & $54(96 \%)$ & $71(78 \%)$ & $\chi^{2}=9.229, \mathrm{p}=0.002^{* * *}$ & $7.61(1.81,32.02)$ \\
\hline
\end{tabular}

"For the sake of clarity, variables with a frequency of an event less than $2 \%$ and some less important variables with insignificant differences between cases and controls are not shown in the table.

"Significant difference 
thetic, total dose of hydroxyethyl starch solution, a history of cardiac arrhythmias in the last 5 years, use of loop diuretics (for at least for 3 months prior to hospitalisation), use of aminophylline (for at least for 3 months prior to hospitalisation), use of digoxin (for at least for 3 months prior to hospitalisation), a history of an abnormal ECG anytime in the last 5 years, intra-operative arrhythmias and serum cholesterol level.

The results of the logistic regression analysis (Cox \& Snell R square 0.356, Nagelkerke R square 0.484, HosmerLemeshow Chi square 7.611, $\mathrm{df}=8, \mathrm{p}=0.472$ ), adjusted for potential confounders, are shown in Table 2. The only significant associations were between early post-operative arrhythmias and a history of cardiac arrhythmias in the last 5 years $\left(\mathrm{OR}_{\text {adjusted }} 8.43\right.$; CI 2.67, 27.13; $\left.\mathrm{p}=0.000\right)$, and between early post-operative arrhythmias and the type of intravenous anaesthetic $\left(\mathrm{OR}_{\text {adjusted }} 0.34 ; \mathrm{CI} 0.12,0.96 ; \mathrm{p}=\right.$ 0.041). After adjusting, the odds ratios for administration of hydroxyethyl starch solution and its total dose, use of loop diuretics, use of aminophylline, use of digoxin, intraoperative arrhythmias, cholesterol level and a history of an abnormal ECG anytime in the last 5 years lost their significance because the confidence level included the value of one (see Tables 1 and 2).

The interaction between risk factors for early postoperative arrhythmias was also investigated (Table 3). Synergistic effects were proven for patients with a history of cardiac arrhythmias in the last 5 years and intra-operative arrhythmias, as well as for patients with a history of cardiac arrhythmias and the type of intravenous anaesthetic used. Although crude odds ratios increased, and their confidence limits excluded the value of one when the interaction of a history of cardiac arrhythmias with the chronic use of digoxin and the chronic use of loop diuretics were excluded, synergistic effects could not be proven by the adjusted odds ratios because the confidence level became wider and included one.

\section{DISCUSSION}

Post-operative arrhythmias are more extensively studied in cardiac surgery patients because there is a higher prevalence of arrhythmias and more serious consequences. The most important risk factors for post-operative arrhythmias in cardiac surgery patients are hypertension, advanced age, hyperlipidaemia, diabetes, a history of smoking and operation time [10,11]. On the other hand, a history of an arrhythmia is a significant risk factor for new peri-operative atrial fibrillation after noncardiac thoracic surgery (two-fold increase in risk)[12], and for other kinds of peri-operative atrial arrhythmias during major elective noncardiac surgery, there is a three-fold increase in risk [13]. In our study, a history of arrhythmias was also associated with early postoperative arrhythmias, but the strength of association between a history of arrhythmias and post-operative arrhythmias was much higher in our study (see Table 2).

A history of arrhythmias and the occurrence of intraoperative arrhythmias were correlated (see Table 3). Although the occurrence of intra-operative arrhythmias was not proved in our study to be an independent risk factor for early postoperative arrhythmias, its interaction with a history of arrhythmia creates a new factor with a strong predictive ability. Recordings of intra-operative arrhythmias and a history of arrhythmias are two factors which, when present together, should be taken seriously by the anaesthesiologists. These patients should be more closely monitored in the early postoperative period so that the appropriate anti-arrhythmic treatments can be administered in a timely manner, if necessary.

In our study, the use of propofol for induction of general anaesthesia increased the risk of early post-operative arrhythmias. Propofol may influence myocardial repolarisation by blocking L-type calcium channels, and by decreasing sympathetic tone and increasing vagal tone [14]. Results of previous studies were not consistent regarding the possibility that propofol prolonged the QT-interval [15]. There are some case

Table 2. Crude and adjusted odds ratios for intra-operative arrhythmia risk factors.

\begin{tabular}{|l|l|l|}
\hline Risk factors & Crude OR $(\mathbf{9 5 \%} \mathbf{C I})$ & Adjusted* OR (95\% CI) \\
\hline History of cardiac arrhythmias & $15.77(6.79,36.64)$ & $8.43(2.67,27.13)$ \\
\hline History of ECG abnormalities & $7.44(3.56,15.54)$ & $1.54(0.47,5.03)$ \\
\hline Type of intravenous anaesthetic (propofol vs. thiopental) & $2.92(1.47,5.79)$ & $0.34(0.12,0.96)$ \\
\hline Hydroxyethyl starch solution administered & $3.14(1.22,8.04)$ & $2.44(0.02,406.97)$ \\
\hline Chronic use of loop diuretics & $5.18(1.90,14.16)$ & $1.45(0.30,7.10)$ \\
\hline Chronic use of digoxin & $4.06(1.33,12.41)$ & $0.79(0.11,5.57)$ \\
\hline Chronic use of aminophylline & $109.20(0.20,56670.27)$ & $541.83(0.00,>10.000)$ \\
\hline Total dose of hydroxyethyl starch solution $(\mathrm{ml} / \mathrm{kg})$ & $1.14(1.00,1.29)$ & $0.91(0.47,1.78)$ \\
\hline Serum level of total cholesterol $(\mathrm{mM} / \mathrm{l})$ & $0.72(0.54,0.95)$ & $0.75(0.52,1.11)$ \\
\hline Intra-operative arrhythmia & $7.61(1.81,32.02)$ & $4.34(0.78,24.26)$ \\
\hline
\end{tabular}

"Adjusted for aget, sex†, type of intravenous anaesthetic, administration of hydroxyethyl starch solution, total dose of hydroxyethyl starch solution, history of cardiac arrhythmias in the last 5 years, use of loop diuretics, use of aminophylline, use of digoxin, history of an abnormal ECG anytime in the last 5 years, serum cholesterol level and intra-operative arrhythmias.

+Crude and Adjusted odds ratios are not shown in the table for the sake of clarity. $\mathrm{OR}=$ odds ratio 
Table 2. Interaction between a history of cardiac arrhythmias in the last 5 years and a history of abnormal ECG anytime in the last 5 years, or the chronic use of loop diuretics, or the type of intravenous anaesthetic, or the chronic use of digoxin.

\begin{tabular}{|l|l|l|}
\hline & Crude odds ratio (95\% CI) & Adjusted* odds ratio (95\% CI) \\
\hline No history of cardiac arrhythmias & 1.0 (reference) & 1.0 (reference) \\
\hline History of cardiac arrhythmias only & $\mathbf{1 5 . 7 7 ~ ( 6 . 7 9 , 3 6 . 6 4 )}$ & $\mathbf{8 . 4 2}(\mathbf{2 . 6 7 , 2 7 . 1 3 )}$ \\
\hline Type of intravenous anaesthetic (propofol vs. thiopental) & $2.92(1.47,5.79)$ & $0.34(0.12,0.96)$ \\
\hline $\begin{array}{l}\text { History of both cardiac arrhythmias and type of } \\
\text { intravenous anaesthetic }\end{array}$ & $4.16(2.45,7.06)$ & $\mathbf{2 . 6 7}(\mathbf{1 . 4 0 , 5 . 0 5 )}$ \\
\hline Chronic use of loop diuretics only & $5.18(1.90,14.16)$ & $1.45(0.30,7.10)$ \\
\hline $\begin{array}{l}\text { Both a history of cardiac arrhythmias and chronic use of } \\
\text { loop diuretics }\end{array}$ & $29.99(3.82,235.63)$ & $11,94(0.98,146.05)$ \\
\hline Chronic use of digoxin only & $4.06(1.33,12.41)$ & $0.79(0.11,5.57)$ \\
\hline $\begin{array}{l}\text { Both a history of cardiac arrhythmias and } \\
\text { chronic use of digoxin }\end{array}$ & $13.44(2.91,62.21)$ & $3.81(0.54,26.87)$ \\
\hline Intra-operative arrhythmias only & $7.61(1.81,32.02)$ & $4.34(0.78,24.26)$ \\
\hline $\begin{array}{l}\text { Both a history of cardiac arrhythmias and intra-operative } \\
\text { arrhythmias }\end{array}$ & $17.74(7.34,42.90)$ & $\mathbf{1 0 . 5 8 ~ ( 3 . 0 3 , 3 6 . 9 2 )}$ \\
\hline
\end{tabular}

"Adjusted for age, sex, type of intravenous anaesthetic, administration of hydroxyethyl starch solution, total dose of hydroxyethyl starch solution, history of cardiac arrhythmias in the last 5 years, use of loop diuretics, use of aminophylline, use of digoxin, history of abnormal ECG anytime in the last 5 years, serum cholesterol level and intra-operative arrhythmias.

reports and observational studies in which it was proposed that propofol may cause intra-operative arrhythmias in conjunction with other acquired or hereditary pro-arrhythmic factors $[16,17,18]$. However, in our study, propofol was used only for the induction of anaesthesia. Taking into account its short elimination half-life (1-3 hours), early post-operative arrhythmias probably were not caused by the direct action of propofol on myocardial cells. The association of propofol and early post-operative arrhythmias might rather explain intraoperative arrhythmias recorded in our patients, which were associated with both propofol and early post-operative arrhythmias. Although we may not know what directly causes early post-operative arrhythmias, in order to avoid them, general anaesthesia induction should be completed with an alternative intravenous anaesthetic, other than propofol.

The chances of early post-operative arrhythmias after noncardiothoracic surgery could be minimizsed by carefully assessing risk factors and avoiding pro-arrhythmogenic drugs during anaesthesia, and consequently providing high-quality patient care.

\section{ACKNOWLEDGEMENTS}

This study was partially financed by grant No. 175007 , given by the Serbian Ministry of Science and Ecology.

\section{REFERENCES}

1. Massin M, Malekzadeh-Milani SG, Demanetz H, Wauthy P, Deuvaert FE, Dessy H, Verbeet T. Prevalence of early postoperative arrhythmias in children with delayed open-heart surgery for severe congenital heart disease. Acta Clin Belg 2010; 65: 386-91.
2. Figas-Powajbo E, Gawor Z, Kozak J. Perioperative cardiac arrhythmias in patients undergoing surgical treatment for lung cancer. Pol Arch Med Wewn 2007; 117: 290-6.

3. Rostagno C, La Meir M, Gelsomino S, Ghilli L, Rossi A, Carone E, Braconi L, Rosso G, Puggelli F, Mattesini A, Stefano PL, Padeletti L, Maessen J, Gensini GF. Atrial fibrillation after cardiac surgery: incidence, risk factors, and economic burden. J Cardiothorac Vasc Anesth 2010; 24: 952-8.

4. O’Kelly B, Browner WS, Massie B, Tubau J, Ngo L, Mangano DT. Ventricular arrhythmias in patients undergoing noncardiac surgery. The Study of Perioperative Ischemia Research Group. JAMA 1992; 268: 217-21.

5. Halm EA, Browner WS, Tubau JF, Tateo IM, Mangano DT. Echocardiography for assessing cardiac risk in patients having noncardiac surgery. Study of Perioperative Ischemia Research Group. Ann Intern Med 1996; 125: 433-41.

6. Burris JM, Subramanian A, Sansgiry S, Palacio CH, Bakaeen FG, Awad SS. Perioperative atrial arrhythmias in noncardiothoracic patients: a review of risk factors and treatment strategies in the veteran population. Am J Surg 2010; 200: 601-5.

7. Eagle KA, Berger PB, Calkins H, Chaitman BR, Ewy GA, Fleischmann KE, Fleisher LA, Froehlich JB, Gusberg RJ, Leppo JA, Ryan T, Schlant RC, Winters WL Jr, Gibbons RJ, Antman EM, Alpert JS, Faxon DP, Fuster V, Gregoratos G, Jacobs AK, Hiratzka LF, Russell RO, Smith SC Jr. ACC/AHA Guideline Update for Perioperative Cardiovascular Evaluation for Noncardiac Surgery-Executive Summary. A report of the American College of Cardiology/American Heart Association Task Force on Practice Guidelines (Committee to Update the 1996 Guidelines on Perioperative Cardiovascular Evaluation for Noncardiac Surgery). Anesth Analg 2002; 94: 1052-64. 
8. Machin D, Campbell MJ, Walters SJ. Medical Statistics, a textbook for the health sciences. $4^{\text {th }}$ edition, John Wiley \& Sons Ltd., Chichester, U.K., 2007.9. Perera R, Heneghan C, Badenoch D. Statistics Toolkit. $1^{\text {st }}$ edition, Blackwell Publishing, Oxford, U.K., 2008.

10. Isobe Z, Suga T, Ohta C, Aoki Y, Aoki F, Maeno T, Kurabayashi $\mathrm{M}$. Clinical investigation of arrhythmia appearing after resection for lung cancer. Nihon Kokyuki Gakkai Zasshi. 2008; 46: 798-802.

11. Galante A, Pietroiusti A, Cavazzini C, Magrini A, Bergamaschi A, Sciarra L, Chartouni G, Legramante JM, Carta S. Incidence and risk factors associated with cardiac arrhythmias during rehabilitation after coronary artery bypass surgery. Arch Phys Med Rehabil 2000; 81: 947-52.

12. Vaporciyan AA, Correa AM, Rice DC, Roth JA, Smythe WR, Swisher SG, Walsh GL, Putnam JB Jr. Risk factors associated with atrial fibrillation after noncardiac thoracic surgery: analysis of 2588 patients. J Thorac Cardiovasc Surg 2004; 127: 779-86.

13. Polanczyk CA, Goldman L, Marcantonio ER, Orav EJ, Lee TH. Supraventricular arrhythmia in patients hav- ing noncardiac surgery: clinical correlates and effect on length of stay. Ann Intern Med 1998; 129: 279-85.

14. Zhou W, Fontenot HJ, Liu S, Kennedy RH. Modulation of cardiac calcium channels by propofol. Anesthesiology 1997; 86: 670-5.

15. Kim DH, Kweon TD, Nam SB, Han DW, Cho WY, Lee JS. Effects of target concentration infusion of propofol and tracheal intubation on QTc interval. Anaeshtesia 2008; 63: 1061-4.

16. Irie T, Kaneko Y, Nakajima T, Saito A, Kurabayashi M. QT interval prolongation and torsade de pointes induced by propofol and hypoalbuminemia. Int Heart J 2010; 51: 365-6.

17. Douglas RJ, Cadogan M. Cardiac arrhythmia during propofol sedation. Emerg Med Australas 2008; 20: 437-40.

18. Wang LY, Ross AK, Li JS, Dearmey SM, Mackey JF, Worden M, Corzo D, Morgan C, Kishnani PS. Cardiac arrhythmias following anaesthesia induction in infantile-onset Pompe disease: a case series. Paediatr Anaesth 2007; 17: 738-48.

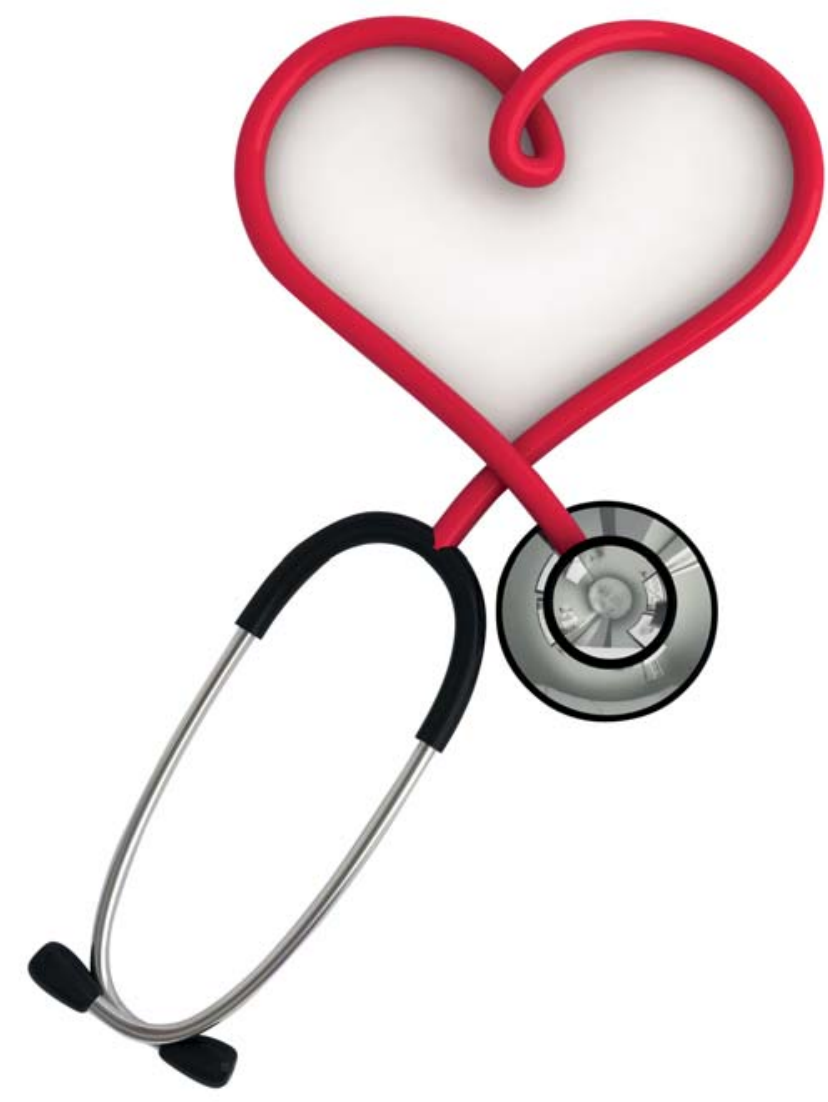

